\title{
Retraction of Published Research
}

d, asatonline.org/for-parents/becoming-a-savvy-consumer/retraction-of-published-research/

David Celiberti, PhD, BCBA-D

Association for Science in Autism

Treatment

Frank Cicero, PhD, BCBA, LBA

Seton Hall University

\section{retraction}

\section{NOUN}

1. the action of drawing something back or back in.

"The pilot retracted the airplane's landing gear."

2. a withdrawal of a statement, accusation, or undertaking.

"The hospital retracted its job offer after learning that the applicant never graduated medical school."

In this installment of Science Corner, we focus on the latter definition of "retraction." The retraction of a published study occurs when the editors of that journal determine that the published findings are not valid. There are several reasons for retractions, including but not limited to, plagiarism, duplicate publication, significant or undeclared conflicts of interest, fraud, ethical breaches, and error. Some of these reasons are associated with incompetence or lack of experience on the part of the researcher, whereas others are more egregious in nature, particularly when there is evidence of deliberate misrepresentations to either secure publication or to purport a specific conclusion. These issues are different from minor errors (e.g., numerical typos) that do not significantly affect the overall findings and implications of the study. In the case of minor errors, a brief correction statement or erratum is typically published to indicate the error that was made. A retraction, however, is a much more serious situation. It is often the last resort by publishers when the results of a study, after investigation, are deemed unreliable and unable to be corrected. Interestingly, there is no legal requirement for a publisher to retract a paper despite finding serious errors in the research (Enago Academy, 2018).

Guidelines for when and how to handle retractions have been established by the Committee on Publication Ethics (COPE). According to COPE, retractions are warranted 
in cases of unreliable findings, plagiarism, and unethical research. It is recommended that the publisher produce a freely available retraction notice that explicitly states the reason for the retraction while keeping the original article available yet watermarked with the word "Retracted." Unfortunately, these COPE guidelines do not seem to be well known to publishers or researchers (Decullier et al., 2013).

There is evidence that the number of retracted publications is increasing such as in cancer research (e.g., Bozzo et al., 2017) and orthopedic research (e.g., Yan et al., 2017). A website dedicated to the archiving of retracted scientific papers,www.retractionwatch.com, found that there were already 37 retracted articles related to COVID-19 at the time of this article. Clearly, the need to retract published works transcends all areas of scientific inquiry. Interestingly, journal quality does not seem to protect against retraction. In fact, there is evidence to show that more retractions are noted to occur within high impact and visible journals than within less rigorous publications (Nath et al., 2006). On a good note, the recent increase seen in retractions is likely due more to increased efforts to identify and address flawed research (i.e. accidental data errors, poor research design, etc.) than to increases in purposeful scientific misconduct (e.g., Vuong, 2019). Despite being properly identified, retracted works can, however, continue to exert a dangerous influence. As you may recall from an article in our previous newsletter, the 2nd author shared his experiences reviewing a research study related to Vitamin D treatment for autism that was ultimately retracted (Cicero, 2020).

With respect to autism, one of the most noteworthy examples of retraction occurred in 2010 when The Lancet, a British medical journal, retracted a 1998 study by Dr. Andrew Wakefield and numerous colleagues which found a link between the MMR vaccine (Measles, Mumps, Rubella) and autism (DeNoon, 2010). In 2004, the vast majority of Wakefield's 13 co-authors of the original study disavowed the findings. Yet, Suezler et al. (2019) found that there were 881 published research articles that cited the article by Wakefield et al. (1998) in the 15-year period since the partial retraction in 2004. What happens to these articles? In 2002, Bernard Rimland and Woody McGinnis published an article in Laboratory Medicine that was based on- and was supportive of- the Wakefield data. Although frequently cited to support the anti-vaccine movement, the article was identified and retracted by the journal. Unfortunately, the retraction did not occur until 2018, 16 years after the original article was published (Ornansky, 2018). This means that the Wakefield data, which were retracted in 2010, technically remained in the literature through the Rimland and McGinnis study until 2018. What, then, about articles that cited Rimland and McGinnis? On a positive note, of the 881 articles that cited Wakefield et al., only $8 \%$ were supportive of the results and interpretation.

Although retracted studies are no longer considered an official part of the scientific literature, the reality is that their impact lingers for a number of reasons: 1) subsequent researchers may not be aware of the retraction; 2) aspects of the work may still influence both research and clinical decision-making; and 3) in the case of printed journals, the hard copies are still accessible in libraries. In fact, Bozzo et al. (2017) found that $29 \%$ of the 571 retracted cancer publications they had identified were still available online in their 
original form.

Where can we go from here? Bozzo et al. (2017) argue that journals should do a better job specifying the reason for retraction and identifying the publication as retracted more clearly. In contrast to COPE guidelines, it is often difficult to find detailed retraction notices for such articles (Decullier et al., 2013). A review of the Web of Science database indicates that notices were issued for only approximately $50 \%$ of retracted studies (Vuong, 2019). A good example of what a retraction notice should look like appears here. Perhaps, more importantly, there are steps that can be taken prior to publication to decrease the need for retraction which includes reinforcing the commitment to academic integrity in the execution of research and preparation of articles submitted for publication (e.g., Yan et al., 2016). Lastly, we encourage our readers to visit the COPE website. Their purpose is to educate and support key stakeholders (e.g., editors, reviewers, and writers) to establish "a culture of publishing" where ethical practices becomes the norm.

Although retraction does not eradicate the influence of the retracted study, it remains a necessary self-correction procedure within the scientific community when the peer review process was shown to be incomplete. Failing to retract a study found to be based on invalid data is clearly more dangerous than issuing the retraction. Publishers, researchers, and consumers of research need to be aware of the concept and process of retraction and what it means with regard to statements made within the retracted study. ASAT will revisit this topic as needed in line with our commitment to celebrating the very best that science has to offer and what that means when we are helping individuals with autism realize their fullest potential.

\section{References}

Bozzo, A., Bali, K., Evaniew, N., \&Ghert, M. (2017). Retractions in cancer research: A systematic survey. Research integrity and peer review, 2, 5. https:/ / doi.org/ 10.1186 / s41073-017-0031-1

Cicero, F. (2020). Perspectives: An unexpected journey into retraction. Science in Autism Treatment, 17(9).

Decullier, E., Huot, L., Samson, G., \&Maisonneuve, H. (2013). Visibility of retractions: a cross-sectional one -year study. BMC Research Notes, 6, 238. https:/ / doi.org/ 10.1186 / 1756-0500-6-238

DeNoon, D.J . (2010, February 2). Study linking autism to vaccine retraction: Retraction follows U.K. finding of 'dishonest, irresponsible' study method. WebMD. https:/ / www.webmd.com/ children/vaccines/ news/ 20100202/ study-linking-autism-tovaccine-retracted.

Enago Academy. (2018, May 4). How should researchers deal with article retractions? https:// www.enago.com/ academy/ how-should-researchers-deal-with-article-retractions/ 
Kern, J . K., Geier, D. A., Deth, R. C., Sykes, L. K., Hooker, B. S., Love, J . M., Bjørklund, G., Chaigneau, C. G., Haley, B. E., \& Geier, M. R. (2017). RETRACTED ARTICLE: Systematic Assessment of Research on Autism Spectrum Disorder and Mercury Reveals Conflicts of Interest and the Need for Transparency in Autism Research. Science and engineering ethics, 23(6), 1689- 1690. https:// doi.org/ 10.1007/ s11948-015-9713-6

Nath, S. B., Marcus, S. C., \&Druss, B. G. (2006). Retractions in the research literature: Misconduct or mistakes? The Medical J ournal of Australia, 185(3), 152- 154.

Oransky, I. (2018, October 16). J ournal retracts 16-year-old paper based on debunked autism vaccine study. Retraction Watch. https:// retractionwatch.com/2018/ 10 / 16/journal-retracts-16-year-old-paper-based-on-debunked-autism-vaccinestudy/ ?fbclid=IwAR3Zu8VgjJ RcAtzhTJjZvHwEw6VVjohTNbDhKGkrwfhwOKSsimHDbb DTQQM

Suelzer, E. M., Deal, J ., Hanus, K. L., Ruggeri, B., Sieracki, R., \& Witkowski, E. (2019). Assessment of citations of the Retracted Article by Wakefield et al with fraudulent claims of an association between vaccination and autism. J AMA network open, 2(11), e1915552. https:// doi.org/ 10.1001/jamanetworkopen.2019.15552

Vuong, Q. (2020). The limitations of retraction notices and the heroic acts of authors who correct the scholarly record: An analysis of retractions of papers published from 1975 to 2019. Learned Publishing, 33(2), 119- 130. https:// doi.org/ 10.1002/leap.1282.

Yan, J ., MacDonald, A., Baisi, L.P. Evaniew, N., Bhandari, M, \& Ghert, M. (2016). Retractions in orthopaedic research: A systematic review. Bone J oint Research, 5, 263- 268. DOI: 10.1302/2046-3758.56.BJ R-2016-0047.

\section{Citation for this article:}

Celiberti, D., \& Cicero, F. (2020). Retraction of Published Research. Science in Autism Treatment, 17(11).

\section{Related ASAT Articles/Resources:}

- An unexpected journey into retraction

- ASD Intervention: How do we measure effectiveness?

- "Verification" and the peer review process

- Media Watch: ASAT Responds to Washington Post story “Lancet Retracts Paper Linking Vaccine to Autism"

- Clinical Corner: Explaining decision to use Science-based autism treatments 